\title{
Propranolol inhibits growth of hemangioma-initiating cells but does not induce apoptosis
}

\author{
Jina J.Y. Kum ${ }^{1}$ and Zia A. Khan ${ }^{1,2}$
}

BACKGROUND: Infantile hemangioma $(\mathrm{IH})$ is the most common tumor of infancy. The first-line therapy for $\mathrm{H}$ is propranolol, a nonselective $\beta$-adrenergic receptor antagonist. However, mechanisms for the therapeutic effect of propranolol and regrowth of $\mathrm{IH}$ following cessation of treatment in some cases are not clear. We have recently shown that $\mathrm{IH}$ arises from multipotent stem cells. Whether $\mathrm{H}$ stem cells are responsive to propranolol and are selectively targeted is unknown, and this is the focus of this study.

METHODS: IH stem cells were exposed to propranolol and were assayed for cellular and molecular alterations. We used endothelial cells (ECS) as controls and bone marrow-derived mesenchymal progenitor cells (bm-MPCs) as normal stem/ progenitor counterparts to determine selectivity.

RESULTS: Our results show that propranolol significantly reduced $\mathrm{IH}$ stem cell growth but failed to induce caspase-3 activation. Normal bm-MPCs and mature ECs showed maintained or increased caspase-3 activation and significantly reduced cyclin-D1 levels. We further show that $\mathrm{IH}$ stem cells may escape apoptosis by inducing antiapoptotic pathways.

CONCLUSION: This study reveals that propranolol does not induce apoptosis in $\mathrm{H}$ stem cells, which is in contrast with the result for ECs. Escape from apoptosis in IH stem cells may involve induction of antiapoptotic pathways.

nfantile hemangioma (IH) is a benign vascular tumor affecting 1 out of 100 newborns $(1,2)$. IH undergoes three developmental phases: a proliferative phase, where the tumor grows rapidly and comprises undifferentiated cells during the first year of life; an involuting phase, where tumor growth slows and vessels become prominent; and an involuted phase, where fibrofatty tissue replaces much of the tumor mass (3). A unique feature only seen in $\mathrm{IH}$ is that the tumor follows this natural course and spontaneously regresses. Hence, most IHs pose no serious threat or complications to the infant; however, in problematic cases that interfere with health and normal function due to the size or location of the tumor, patients may require immediate treatment (4). For example, obstructive $\mathrm{IH}$ in organs such as the eyes or the airway require immediate attention because the tumor may inhibit normal development and function of the organ and impair the infant permanently $(3,5)$.
Current treatments for IH include surgery when necessary and use of corticosteroids, despite the severe side effects when taken for extended periods at high doses. Recently, propranolol was discovered to be an effective treatment for IH (6), with higher efficacy and minimal side effects when compared with corticosteroids (7). Propranolol is a nonselective $\beta$-adrenergic receptor antagonist that has been widely used for complications such as angina pectoris, myocardial infarction, and hypertension. Although the mechanism of therapeutic effect of propranolol is unknown, theories suggest vasoconstriction, endothelial cell (EC) apoptosis, and inhibition of angiogenesis by modulating vascular endothelial growth factors (8-11). In fact, a number of recent studies have shown that propranolol treatment of both normal ECs and ECs derived from IH specimens causes activation of caspase- $3(12,13)$. Caspase- 3 is an important regulator of cellular apoptosis and is recognized as an indispensable death protease for apoptotic chromatin condensation and DNA fragmentation in all cell types examined (reviewed in ref. (14)). In addition to inducing apoptosis, propranolol also decreases the expression of various cyclins in ECs, thus disrupting cell cycle progression and growth (12).

A puzzling finding from a few propranolol treatment studies in patients is that some IHs regrow on cessation of propranolol treatment (15-17). This has been attributed to early treatment withdrawal and/or a long proliferating phase of $\mathrm{IH}$. Previously, we have shown that $\mathrm{IH}$ arises from multipotent stem cells (termed hemSCs for hemangioma-derived stem cells)(18). HemSCs, isolated based on expression of stem cell antigen CD133, form glucose transporter-1-positive microvessels in immunodeficient mice. These glucose transporter-1-positive vessels are later replaced by human adipocytes that mimic the natural stages of human $\mathrm{IH}$. Interestingly, IH-derived ECs are unable to produce microvessels (18). This suggests that hemSCs may be responsible for the recurrence of $\mathrm{IH}$ on cessation of propranolol treatment, possibly owing to the nonresponsiveness of hemSCs to propranolol. In this study, we have explored this possibility by treating primary hemSCs with propranolol to determine whether propranolol induces caspase-3 activation and apoptosis, as has been shown for vascular ECs. We have also studied bone marrow-derived mesenchymal progenitor cells (bm-MPCs) as normal counterparts of hemSCs 
to determine whether changes (if any) observed in hemSCs are specific or whether the response depends on the stem/progenitor phenotype. In addition, we investigated possible signaling pathways involved on propranolol treatment.

\section{RESULTS}

\section{Atypical Phenotype of IH Endothelium}

A number of studies have investigated the effect of propranolol on IH-derived ECs to offer insight into the mechanisms of therapeutic effect of propranolol $(12,13,19)$. These studies show that propranolol causes apoptosis in IH ECs by activating caspase- 3 and blocks other cellular activities including migration and tubule formation $(12,13)$. This effect of propranolol is also exhibited by normal ECs $(9,12)$. We have shown that $\mathrm{IH}$ arises from multipotent stem cells (18). CD133-positive cells from human IH produce hemangioma lesions in mice. Interestingly, IH-derived ECs (exhibiting mature endothelial phenotype as assessed by EC markers) fail to produce glucose transporter-1-positive microvessels (18). This suggests that the cell of interest, at least in proliferating-phase $\mathrm{IH}$ when treatments are required, is the hemSC. Therefore, we performed immunostaining for CD133 to probe for the number of microvessels that are lined by CD133-expressing cells. Results from two proliferating IH specimens show that all microvessels within IH tissues are immunoreactive to CD133 (Figure 1). This suggested that for understanding the effect of propranolol, CD133-positive hemSCs are essential.

\section{$\beta 2$ and $\beta 3$ Are the Predominant $\beta$-Adrenergic Receptors in IH Stem Cells}

We first assayed for $\beta$-adrenergic receptor expression in hemSCs and compared the levels with those in mature ECs. Our results show that hemSCs express both $\beta 2$ - and $\beta 3$-adrenergic receptors (Figure 2a). $\beta 1$-adrenergic receptor mRNA levels, although detectable, were significantly lower. Interestingly, we found that bm-MPCs share $\beta$-adrenergic receptor profile with hemSCs. Mature ECs (human microvascular ECs; human dermal microvascular ECs (HDMECs)) on the other hand exhibited higher level of $\beta 1$-adrenergic receptor expression

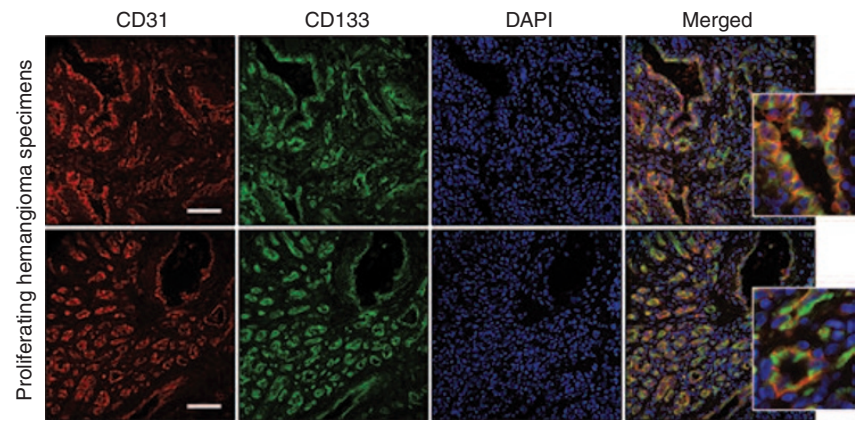

Figure 1. CD133-positive cells line hemangioma vessels. Proliferating hemangioma specimens were double labeled for CD31 (endothelial cell marker; red) and CD133 (stem cell antigen; green). 4',6-Diamidino-2phenylindole (blue) was used as counterstain. Staining illustrates complete colocalization of CD133 and CD31 in both proliferating hemangioma specimens (images were taken at magnification of $\times 20$; insets illustrate high magnification; bar $=200 \mu \mathrm{m}$ ).
(Figure 2a). No significant differences were found in the level of $\beta 2$ - or $\beta 3$-adrenergic receptors between ECs, hemSCs, and bm-MPCs.

\section{Propranolol Inhibits IH Stem Cell Growth}

Our next objective was to determine the effect of propranolol on the growth of hemSCs. We cultured the cells with 25, 50 , and $100 \mu \mathrm{mol} / \mathrm{l}$ propranolol and assayed for cell number at both 24 and $72 \mathrm{~h}$. We chose these concentrations based on previous studies that have observed significant differences in IH ECs $(9,12)$. Furthermore, propranolol has been shown to have immediate effects in inhibiting cell viability at $24 \mathrm{~h}$ (13). Interestingly, no significant changes in cell number were observed in any cell type at $24 \mathrm{~h}$ (data not shown). At $72 \mathrm{~h}$, however, bm-MPCs and HDMECs showed significant
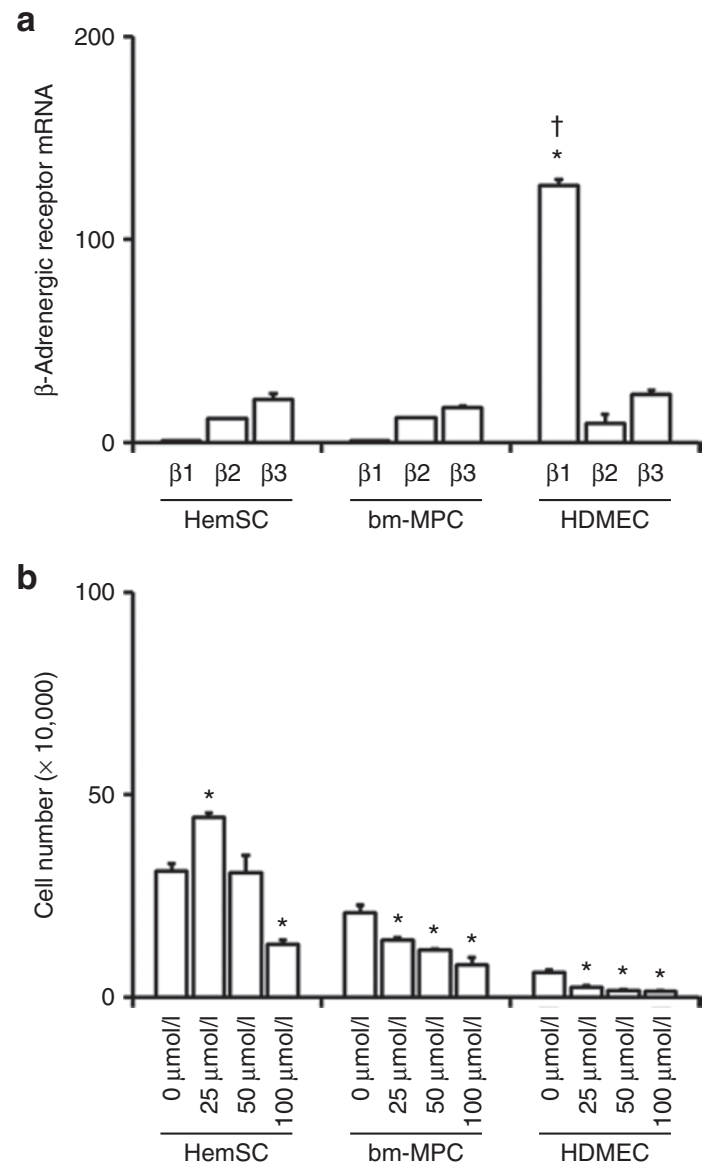

Figure 2. Propranolol reduces hemangioma-derived stem cell (hemSC) growth. (a) mRNA levels of $\beta$-adrenergic receptors in CD133-positive hemSCs, normal bone marrow-derived mesenchymal progenitor cells (bm-MPCs), and human dermal microvascular endothelial cells (HDMECs) were determined by real-time quantitative reverse-transcriptase PCR (data normalized to $\beta$-actin; ${ }^{*} P<0.05$ compared with $\beta 1$-adrenergic receptor mRNA levels in hemSCs and bm-MPCs; ${ }^{+} P<0.05$ compared with $\beta 2$ - and $\beta 3$-adrenergic receptor mRNA levels). RNA was isolated from cells cultured in Endothelial Basal Media-2 (EBM2) under identical conditions. The specificity of the amplification was determined by melting curve analysis (data not shown). (b) Total live cell number after $72 \mathrm{~h}$ of treatment with different concentrations of propranolol. Propranolol treatment at $100 \mu \mathrm{mol} / \mathrm{I}$ showed reduced number of cells compared with control in all cell types tested $\left({ }^{*} P<0.05\right.$ compared with respective control). 
reductions in cell number at all concentrations of propranolol when compared with control (Figure $2 \mathbf{b}$ ). In contrast, a proliferative effect was observed when hemSCs were treated with 25 $\mu \mathrm{mol} / \mathrm{l}$ propranolol, and a reduction in total live cell number was observed with $100 \mu \mathrm{mol} / \mathrm{l}$ propranolol (Figure $2 \mathrm{~b}$ ).

\section{Reduced Cell Number Following Propranolol Treatment Is Not Due to Apoptosis in IH Stem Cells}

Because the cell number decreased significantly for all cell types when cultured in $100 \mu \mathrm{mol} / \mathrm{l}$ propranolol (at $72 \mathrm{~h}$ ), we examined whether this was due to apoptosis. Therefore, cells treated with propranolol were assayed for active caspase-3. Caspase- 3 is the most frequently activated death protease and plays a role in inducing EC apoptosis on propranolol treatment $(12,13)$. Unexpectedly, hemSCs treated with $100 \mu \mathrm{mol} / \mathrm{l}$ propranolol showed a significant reduction in the level of active caspase-3. This suggested that in hemSCs, the reduction in cell number might be due to inhibited cell growth and not apoptosis. bm-MPCs did not show a significant difference on propranolol treatment as caspase-3 levels remained unchanged (Figure 3a). On the other side of the spectrum, propranololtreated HDMECs showed a significant increase in the level of activated caspase-3 as expected. These data demonstrate that propranolol treatment induces apoptosis in HDMECs, whereas the decrease in cell number in hemSCs - and possibly bm-MPCs-is mediated by a reduction in cell growth.

\section{Propranolol Halts Cell Cycle Progression but Does Not Induce Apoptosis in hemSCs}

We examined the effect of propranolol on cyclin-D1 levels. Cyclin-D1 is a key regulator in the progression from G1/S phase and has recently been shown to be maintained in the G2 phase (20). Recent studies have shown that propranolol reduces cyclin-D1 in a time-dependent manner in ECs (9). Surprised by previous experimental findings, we wanted to determine whether propranolol reduces cyclin-D1 in hemSCs. Our results do show significantly reduced cyclin-D1 in hemSCs on propranolol treatment (Figure 3b). Similarly, cyclinD1 levels in bm-MPCs and HDMECs were also significantly reduced (Figure $3 \mathbf{b}$ ). The greatest change in cyclin-D1 was seen in bm-MPCs, which may explain the reduced cell number seen earlier. These results suggest that propranolol inhibits cell cycle progression in all cell types by decreasing the level of cyclin-D1.

\section{Propranolol Induces Antiapoptotic Pathways in hemSCs}

To understand the possible mechanism by which propranolol induces apoptosis in ECs but not in hemSCs, we used quantitative reverse-transcriptase PCR (RT-PCR) to obtain the profiles of genes important in the central mechanisms of cellular death. We used Human Cell Death Pathway Finder PCR Array (Qiagen, Mississauga, ON; see Methods section for details), which comprises 84 key genes important for cell survival and apoptosis. HemSCs, bm-MPCs, and HDMECs were cultured in normal growth media or in media containing different concentrations of propranolol for $72 \mathrm{~h}$. Using this PCR-based

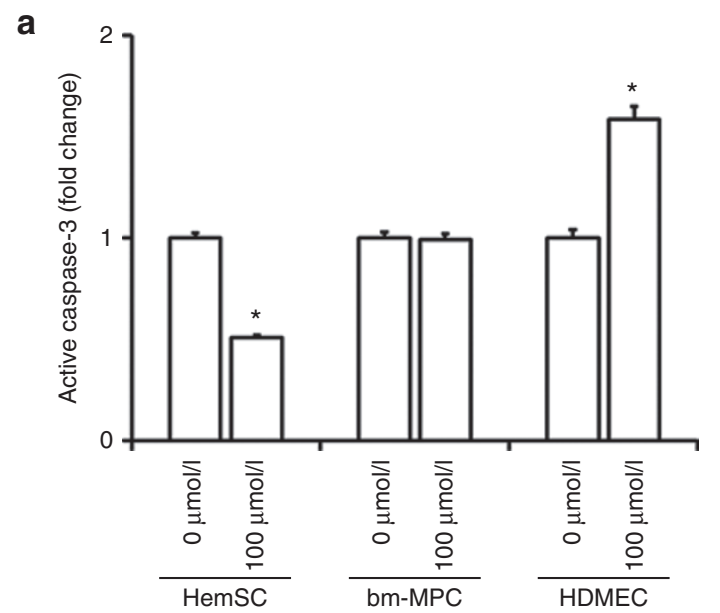

b

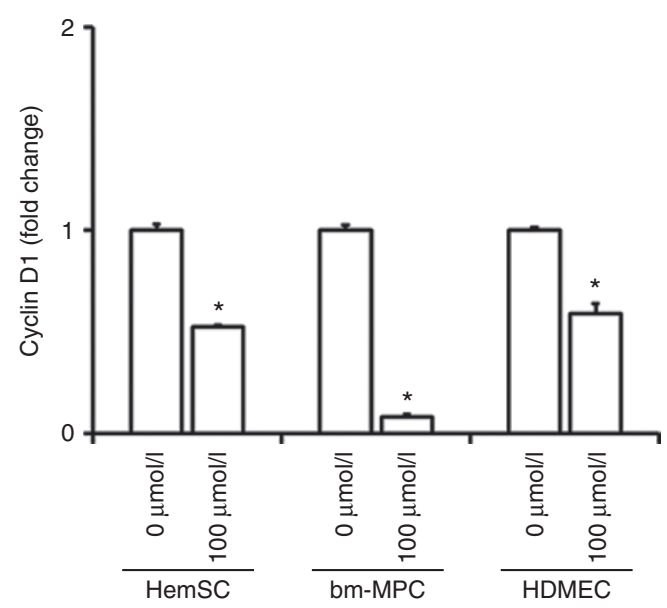

Figure 3. Propranolol reduces active caspase-3 level in hemangiomaderived stem cells (hemSCs). Levels of (a) activated caspase-3 and (b) cyclin-D1 in hemSCs, bone marrow-derived mesenchymal progenitor cells (bm-MPCs), and human dermal microvascular endothelial cells (HDMECs) following $100 \mu \mathrm{mol} / \mathrm{l}$ propranolol treatment for $72 \mathrm{~h}\left({ }^{*} P<0.05\right.$ compared with respective $0 \mu \mathrm{mol} / /$ treatment/control).

array, we found that propranolol significantly induces various antiapoptotic pathways in hemSCs and normal bm-MPCs (Figure 4a). These included Akt (also known as protein kinase $\mathrm{B}$; induced $31.2 \times$ in hemSCs and $7.58 \times$ in bm-MPCs), $\mathrm{Bcl} 2$ (induced $295.9 \times$ in hemSCs and $143.2 \times$ in bm-MPCs)/Bcl $2 \mathrm{~A}$ (induced 23.47 $\times$ in hemSCs and $10.97 \times$ in bm-MPCs), and insulin-like growth factor receptor-1 (IGFR-1; induced 53.68× in hemSCs and 9.29× in bm-MPCs). In contrast, we did not observe any alterations of these antiapoptotic pathways in HDMECs (Figure 4a).

\section{TNF- $\alpha$, but Not IFN- $\boldsymbol{\gamma}$, Reduced Cell Growth in IH Stem Cells}

In addition to inducing antiapoptotic pathways, we observed that propranolol treatment significantly increased tumor necrosis factor (TNF) pathway members and interferon- $\gamma$ (IFN- $\gamma$ ) in hemSCs and, to a lesser degree, in bm-MPCs (Figure $4 \mathbf{b}, \mathbf{c}$ ). This led us to question whether TNF or IFN signaling mediates the changes that we have observed in hemSCs on propranolol challenge. We first determined the effect 


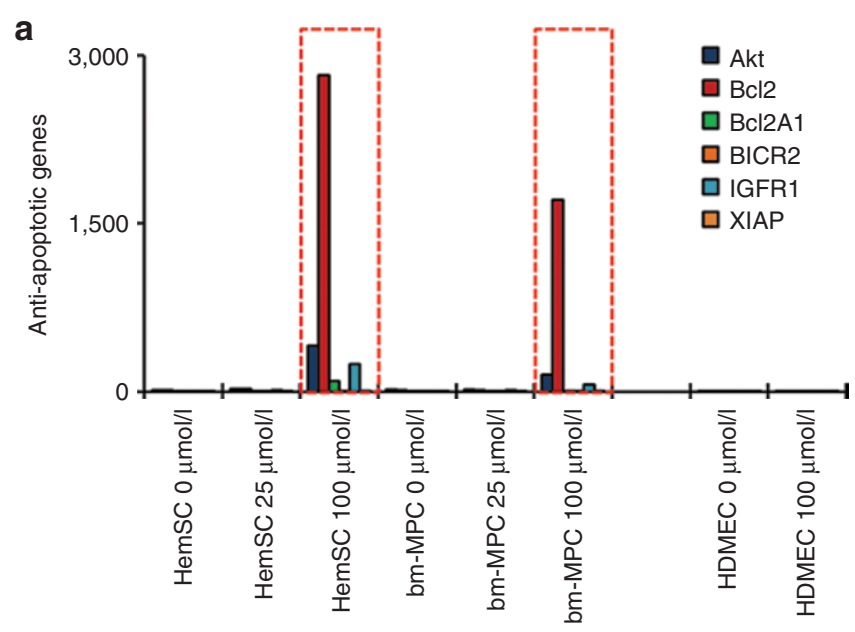

b

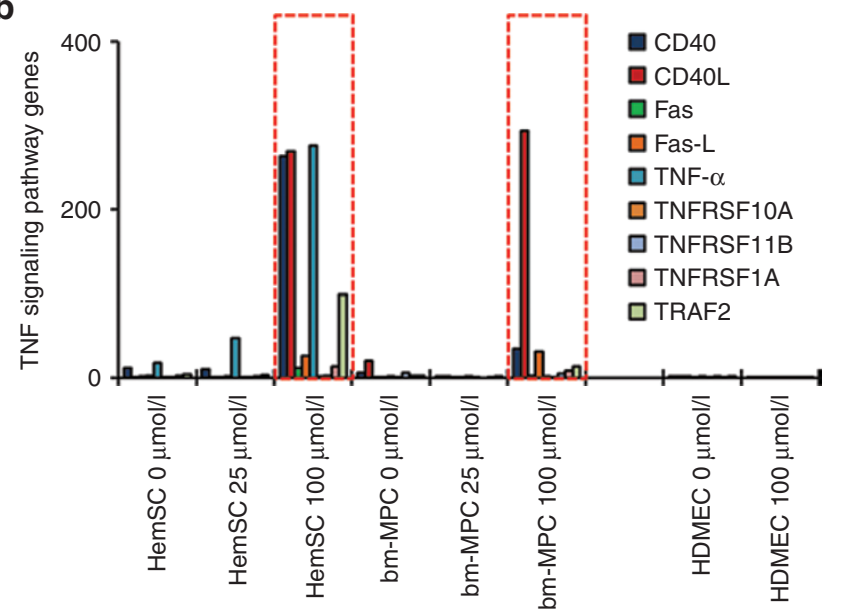

C

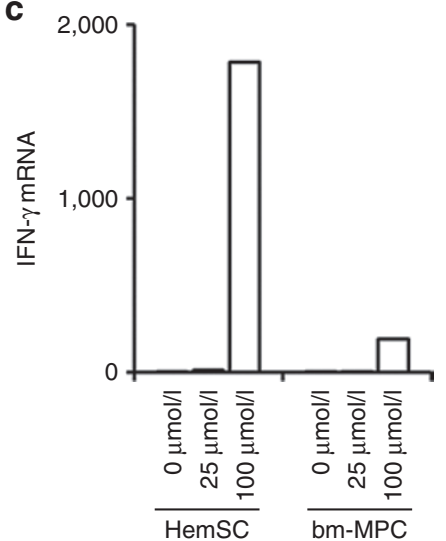

Figure 4. Propranolol induces antiapoptotic signaling pathways in hemangioma-derived stem cells (hemSCs). Propranolol induced the expression of (a) antiapoptotic genes, (b) tumor necrosis factor (TNF) superfamily signaling pathway, and (c) interferon- $\gamma($ IFN- $\gamma$ ) in hemSCs and bone marrow-derived mesenchymal progenitor cells (bm-MPCs) but not in human dermal microvascular endothelial cells (HDMECs) (mRNA levels were measured using $\mathrm{RT}^{2}$ Cell Death Pathway Finder (Qiagen, Mississauga, ON) and normalized to $\beta$-actin and glyceraldehyde 3-phosphate dehydrogenase levels; red dashed lines in panels a and $\mathbf{b}$ highlight $100 \mu \mathrm{mol} / \mathrm{l}$ propranolol groups; graphs shown in $\mathbf{a}-\mathbf{c}$ are representative of multiple PCR arrays). of exogenous TNF- $\alpha$ treatment on hemSCs. Interestingly, there was a significant cell number reduction in hemSCs on exposure to 50 and $100 \mathrm{ng} / \mathrm{ml} \mathrm{TNF-} \alpha$ (Figure $5 \mathrm{a}$ ). We then investigated the effect of TNF- $\alpha$ on activated caspase- 3 level in hemSCs. If propranolol is acting through the TNF- $\alpha$ pathway, then we would expect no increase in caspase-3 activity. Indeed, our results show that TNF- $\alpha$-treated hemSCs did not show changed active caspase- 3 level when compared with control (Figure 5b). We then tested the possible involvement of IFN$\gamma$ by exposing hemSCs and bm-MPCs to exogenous IFN- $\gamma$. Our studies show no significant effect on hemSC or bm-MPC growth at 24 or $72 \mathrm{~h}$ (Figure $5 \mathrm{c}, \mathbf{d}$ ). This suggests that TNF- $\alpha$, but not IFN- $\gamma$, has an antiproliferative effect in vitro and may be involved in propranolol's action.

\section{Propranolol-Induced Altered Differentiation in hemSCs}

While our studies were underway, a report showed that presence of propranolol in adipogenic differentiation media increased the differentiation level in hemSCs compared with the differentiation level in cells grown in adipogenic media alone (21). Higher levels of CCAAT-enhancer-binding protein $\beta(\mathrm{C} / \mathrm{EBP} \beta)$ and $\delta$ were found at day 4 . Interestingly, when the cells were maintained in the differentiation media supplemented with propranolol for $7 \mathrm{~d}$, significant cell death was observed. This is in contrast with our observations in normal growth media where a significant reduction in cell number is evident without apoptosis. Therefore, we explored the possibility that this enhanced adipogenic differentiation with propranolol is mediated through cell growth regulation. To test this idea, we treated hemSCs with mitomycin $\mathrm{C}$ to inhibit proliferation and tested for C/EBP expression. Our results show that $\mathrm{C} / \mathrm{EBP} \alpha$ was significantly higher when mitomycin $\mathrm{C}$-treated hemSCs were exposed to adipogenic differentiation media for $4 \mathrm{~d}$ (Figure 6a). No change was observed in peroxisome proliferator-activated receptor- $\gamma$ $(\operatorname{PPAR} \gamma 2)$ levels. $\mathrm{C} / \mathrm{EBP} \alpha$ is a critical transcription factor in adipogenesis and enhanced levels suggest that inhibition of cell proliferation increases the differentiation capacity of hemSCs, and this may be the mechanism underlying propranolol's effect. We then assayed for $\beta$-adrenergic receptor expression and show here that adipogenesis is associated with significantly higher levels of all three adrenergic receptors (Figure 6b). Therefore, cell death in adipogenic media supplemented with propranolol (21) might be due to increased expression of $\beta$-adrenergic receptors, which accompanies hemSC differentiation.

\section{DISCUSSION}

Propranolol is now widely used for treating $\mathrm{IH}$; however, the mechanism of its therapeutic effect is still unknown. In addition, some IHs regrow after stoppage of propranolol treatment (15-17). In this study, we have demonstrated that propranolol does not induce apoptosis in hemSCs, cells responsible for $\mathrm{IH}$ initiation, as seen in mature/differentiated ECs. This suggests that the direct effect of propranolol in IHs may be through both modulation of mature ECs and angiogenesis (Figure 7a). 

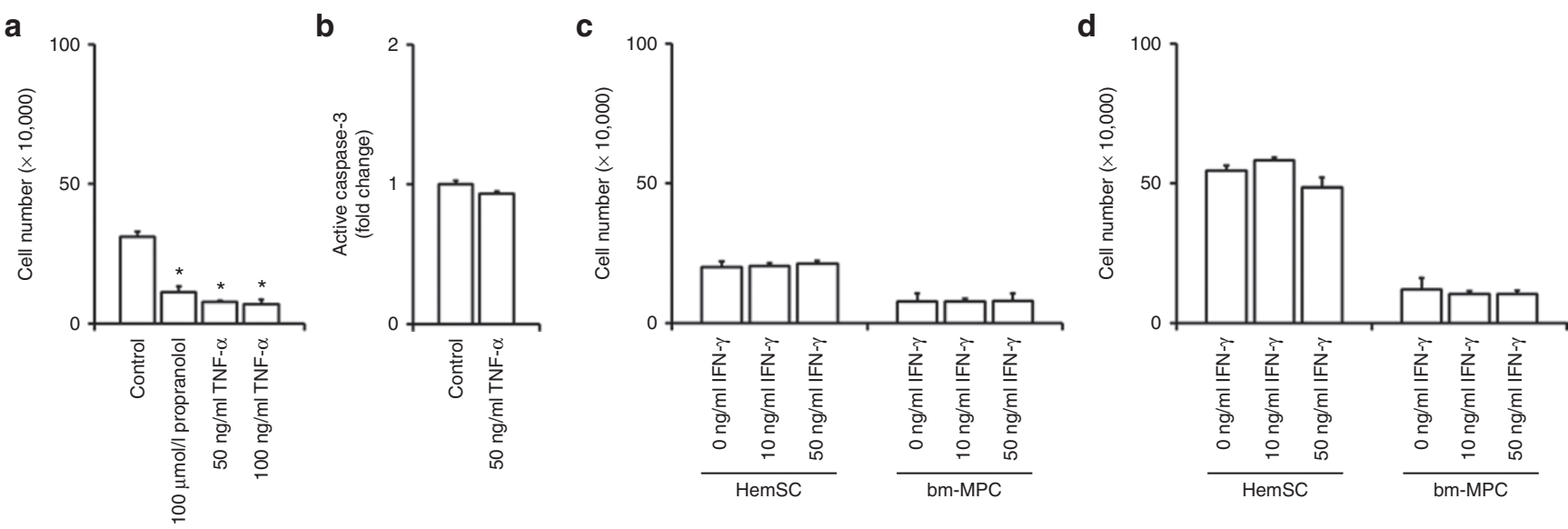

Figure 5. Tumor necrosis factor (TNF) activation leads to reduced cell growth in hemSCs. TNF- $\alpha$ treatment significantly reduced cell number (a) in hemSCs after $72 \mathrm{~h}$ but did not change (b) activated caspase-3 level $\left({ }^{*} P<0.05\right.$ compared with control). HemSCs treated with interferon- $\gamma($ IFN- $\gamma$ ) showed no significant change in cell number after (c) 24 or (d) 72 h. bm-MPCs, bone marrow-derived mesenchymal progenitor cells; hemSCs, hemangioma-derived stem cells.

The mechanism by which hemSCs and possibly normal progenitor cells (modeled here by bm-MPCs) escape apoptosis may include induction of antiapoptotic pathways. We found Akt, $\mathrm{Bcl} 2 / \mathrm{Bcl} 2 \mathrm{~A}$, and IGFR-1 to be significantly induced in hemSCs and bm-MPCs. Akt induction is of particular importance here as this prosurvival kinase counteracts caspase-3 activity (22-24). Bcl2 downregulation has been shown to increase caspase-3 in breast cancer cells (25). Furthermore, Bcl2A mediates the antiapoptotic effects of fibroblast growth factor in chondrogenic progenitor-like cell lines (26). Therefore, these pathways may be involved in reducing/counteracting caspase- 3 activity in hemSCs but not in mature ECs.

We also examined whether the extrinsic apoptotic pathway is involved in propranolol-induced growth inhibition. The extrinsic pathway is primarily mediated by the TNF superfamily. We found that TNF signaling pathway genes (listed in Figure $4 \mathrm{~b}$ ) are also upregulated in hemSCs and bm-MPCs on propranolol treatment. Because it is well known that TNF signaling pathways are involved in cell death, these results were unexpected. However, recent studies show that TNF's effect may not be limited to cell apoptosis. TNF- $\alpha$ causes cell cycle arrest, but not death, in keratinocytes (27), glioblastoma cells (28), and melanoma cell lines (29). These findings suggest two independent antiproliferative mechanisms of TNF signaling. In hemSCs, TNF signaling may be involved in propranololmediated cell cycle arrest. Indeed, when we treated hemSCs to exogenous TNF- $\alpha$, we noted decreased cell growth over $72 \mathrm{~h}$ but no change in caspase-3 activity. Taken together with the results of antiapoptotic gene induction, we believe propranolol may reduce hemSC growth by inducing the TNF pathway and may facilitate the escape from caspase-3 activation and apoptosis by TNF-independent induction of antiapoptotic genes.

Another interesting finding of this study is that hemSCs predominantly express $\beta 2$ - and $\beta 3$-adrenergic receptors. $\beta 1$ receptor levels are almost 10-fold lower. Vascular ECs, on the other hand, express significantly high levels of $\beta 1$ receptor compared with $\beta 2 / 3$. These findings suggest that the differential effect of propranolol in hemSCs and ECs may be due to the distinct roles of the $\beta$-adrenergic receptor subtypes. Communal et al. (30) have shown that activation of $\beta 1$ receptors on cardiac myocytes induces apoptosis, whereas activation of $\beta 2$-adrenergic receptor opposes cell death. Although this study involved activation of $\beta$-adrenergic receptor and not antagonism, the concept of a distinct, receptor subtypespecific role is pertinent here. Moreover, Panjala et al. (31) have demonstrated that $\beta 1$-adrenergic receptor knockout mice exhibit increased formation of degenerate capillaries in the retina. These are interesting findings because retinal ECs express $\beta 1$-, but not $\beta 2$-, adrenergic receptors (32). Also associated with acellular capillaries in the retina in knockout mice were increased level of cleaved caspase-3. Based on our data, we suggest that antagonizing $\beta 1$ receptor in $\mathrm{IH}$ cells is associated with cell death, whereas $\beta 2$ is involved with cell cycle regulation (Figure $7 b$ ). We know that hemSCs predominantly express $\beta 2$ and $\beta 3$ receptors and show almost 10 -fold lower $\beta 1$ levels. bm-MPCs showed a similar response to propranolol in terms of cellular activity and molecular alterations and share the $\beta$-adrenergic receptor profile of hemSCs.

Wong et al. (21) have recently shown that propranolol enhances adipogenesis in hemSCs. Specifically, presence of propranolol in adipogenic media initially caused differentiation of hemSCs but significant cell death at day 7 (21), which is the typical in vitro time for full functional adipocyte differentiation. We reasoned that the initial effect of propranolol might be mediated through cell cycle disruption. To test this possibility, we treated hemSCs with mitomycin $\mathrm{C}$ before exposing the cells to adipogenic differentiation media. We noted that mitomycin C-treated cells had significantly higher levels of $\mathrm{C} / \mathrm{EBP} \alpha$ induction, suggesting that enhanced adipogenesis in hemSCs may be related to a change in the differentiation timeline (reduced growth and earlier differentiation). We also tested whether adipogenesis itself alters $\beta$-adrenergic receptor expression in hemSCs, thereby making cells more sensitive to propranolol and possibly explaining cell death observed in the 

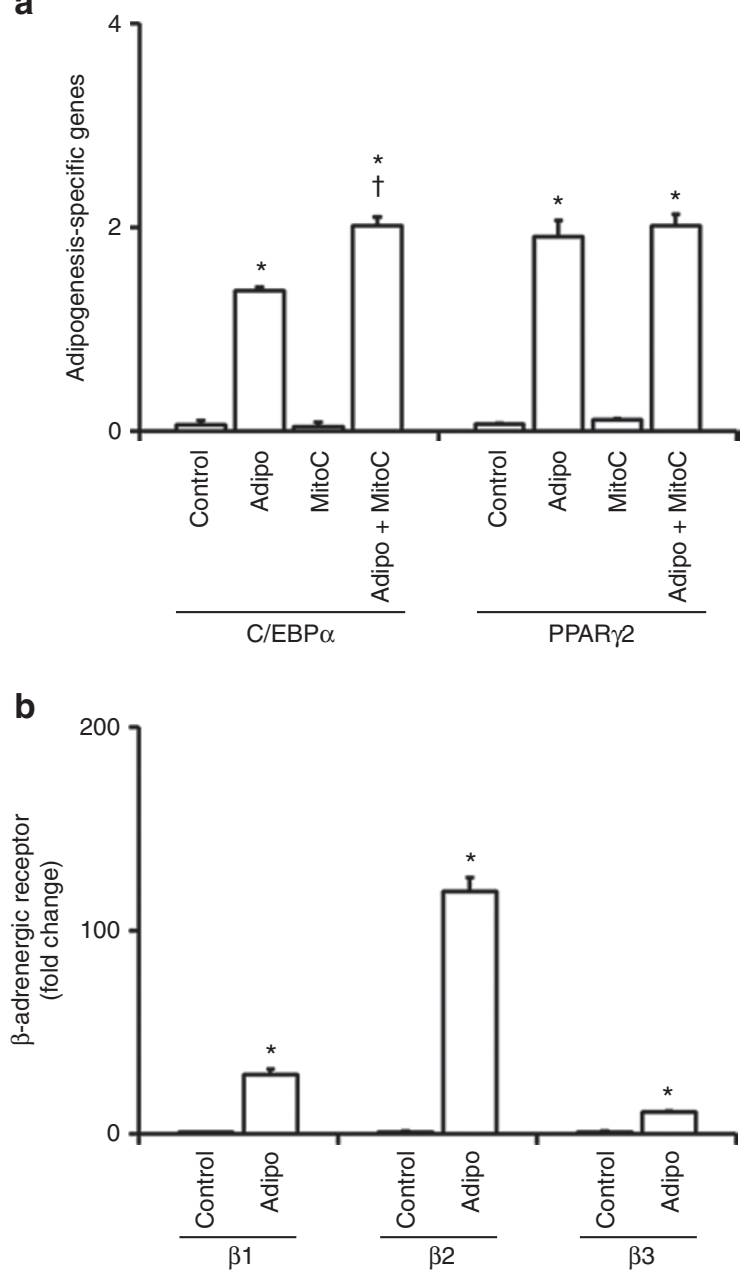

Figure 6. Growth inhibition enhances adipogenesis. Effect of mitomycin $C$ treatment on adipogenic differentiation (a) in hemSCs at day 4 (Adipo, adipogenic media; MitoC, mitomycin $C$; ${ }^{*} P<0.05$ compared with control media; ${ }^{\dagger} P<0.05$ compared with adipogenic differentiation media without mitomycin $C$ treatment). (b) Induction of $\beta$-adrenergic receptors following adipogenic differentiation in hemSCs at day 7 (Adipo, adipogenic media; ${ }^{*} P<0.05$ compared with control media).

previous study (21). Indeed, differentiation of hemSCs significantly increased the expression of all $\beta$-adrenergic receptor subtypes, including $\beta 1$. Therefore, cell death seen in adipocytes may be associated with the increase in $\beta 1$ receptor expression (29.47-fold increase, as reported in our study). Increased level of $\beta 2$ receptors in adipocytes may further enhance the inhibitory process by regulating cell cycle progression.

Our study represents an important step toward understanding the mechanism of propranolol action. A number of pressing questions remain. For example, is propranolol selective to IH vessels? Based on recent findings in ECs (normal vs. IH-derived) and our own findings in hemSCs, this seems unlikely. Alternatively, the effectiveness of propranolol in IHs may be a function of increased levels that are sustained in the capillary mass of IHs. These studies are under way in our laboratory, and the findings may enhance our understanding of the mechanism of therapeutic action of propranolol and may provide more effective treatment options.
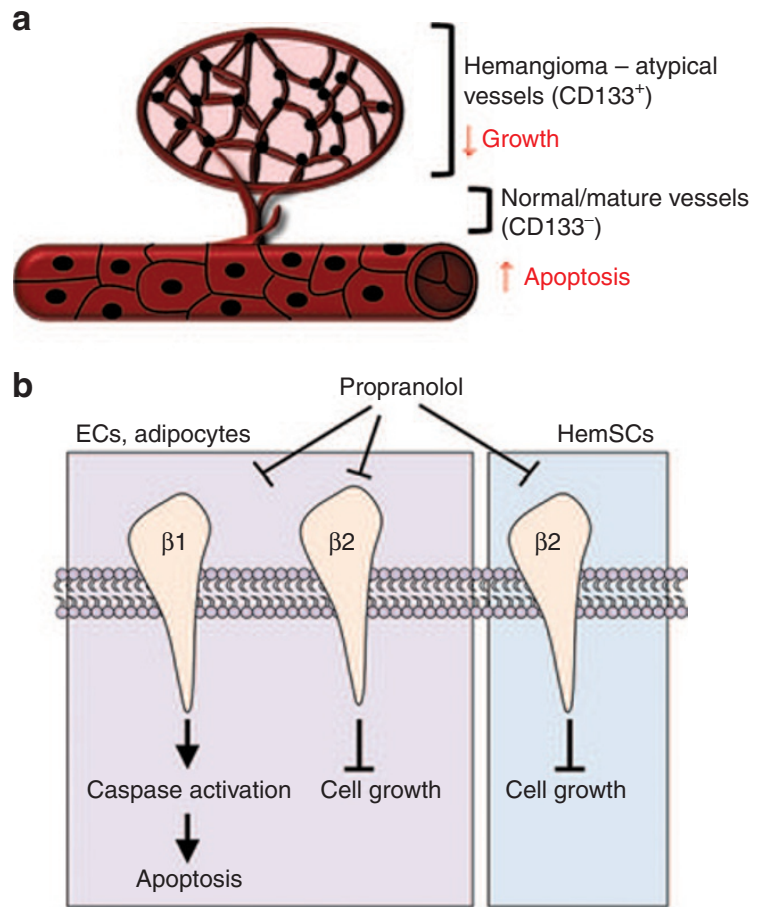

Figure 7. Proposed mechanism of therapeutic effect of propranolol. Schematic representation illustrating the proposed mechanism of propranolol action on hemSCs and mature endothelial cells (ECs). (a) Schematic diagram illustrating the penetrance of apoptotic effect of propranolol in hemangioma regression. (b) Propranolol leads to cell apoptosis in endothelial cells and other mature cell types, including adipocytes, through alteration of $\beta 1$-adrenergic receptor signaling. Engagement of $\beta 2$ - (and possibly $\beta 3$-) adrenergic receptors leads to cell cycle arrest and growth inhibition.

\section{METHODS}

\section{IH Specimens and Immunostaining}

We obtained paraffin-embedded IH specimens from the Department of Pathology Archives at the London Health Sciences Centre (London, Ontario, Canada). The proliferating phase was confirmed by histological analysis. Tissue sections were deparaffinized, hydrated, and subjected to antigen retrieval using Tris/EDTA buffer (10 mmol/l Trizma base, $1 \mathrm{mmol} / \mathrm{l} \mathrm{EDTA}, 0.05 \%$ Tween-20, pH 9.0) in 2100 Retriever (Electron Microscopy Sciences, Hatfield, PA). To perform double staining, we incubated slides with mouse anti-human CD31 (1:50; M0823, Dako, Canada, Mississauga, ON) and rabbit anti-human CD133 antibody (1:100; ab19898, Abcam, Cambridge, MA) for $1 \mathrm{~h}$ at room temperature. Fluorescein- or Texas Red-conjugated secondary antibodies (Vector Laboratories, Burlington, ON) were used for detection. Slides were counterstained with 4',6-diamidino-2-phenylindole (Vector Laboratories). Images were taken using an Olympus BX-51 microscope (Olympus Canada, Richmond Hill, ON) equipped with a Spot Pursuit digital camera (SPOT Imaging Solutions, Sterling Heights, MI).

\section{IH Cell Isolation and Culture}

Proliferating IH-derived $\mathrm{CD} 133^{+}$cells (hemSCs) were kindly provided by Dr. Joyce Bischoff (Children's Hospital Boston, Boston, MA). We have previously shown full characterization of hemSCs and culture conditions (18). Freshly isolated bm-MPCs (isolated from bone marrow-derived mononuclear preparations; $2 \mathrm{M}-125 \mathrm{~B}$, Lonza, Walkersville, MD) were used as normal stem/progenitor controls. Neonatal HDMECs (CC-2516, Lonza) were also used as controls. Previous studies have compared normal ECs with IH-derived mature ECs and have shown striking similarity in propranolol response $(9,12,13)$. All cells were cultured on fibronectin-coated (FN; 
$1 \mu \mathrm{g} / \mathrm{cm}^{2}$, FC010-10, Millipore, Temecula, CA) plates in Endothelial Basal Media-2 (Lonza) supplemented with $20 \%$ fetal bovine serum (Lonza) and SingleQuots (CC-4176, Lonza) and $1 \times$ antibiotic antimycotic media (Penicillin-Streptomycin-Fungizone, PSF; Life Technologies, Burlington, ON). All cells were cultured under identical conditions, and experiments were performed with a minimum of two biological replicates (different IH cell preparations) and three technical replicates. All studies were conducted following approval by the Research Ethics Board at The University of Western Ontario, London, Ontario, Canada.

\section{Cell Growth Assay}

To determine the effect of propranolol on cell growth, we plated each cell type at $5,000 \mathrm{cell} / \mathrm{cm}^{2}$ in complete endothelial growth medium (described above). After $24 \mathrm{~h}$, the medium was removed and cells were exposed to 25,50 , or $100 \mu \mathrm{mol} / \mathrm{l}(\mathrm{R})-(+)$-propranolol hydrochloride (Propranolol; 0624, R\&D Systems, Minneapolis, MN) in fresh media. Total number of live cells was determined at 24 or $72 \mathrm{~h}$ using Scepter 2.0 Automated Cell Counter (Millipore) with appropriate histogram gating setup $(33,34)$. For some experiments, hemSCs and bmMPCs were treated with IFN- $\gamma$ (285-IF-100, R\&D systems) or TNF- $\alpha$ (210-TA-010/CF, R\&D systems) for up to $72 \mathrm{~h}$.

\section{RNA Isolation, mRNA Profiling, and Quantitative RT-PCR}

RNA was isolated using RNeasy Micro Plus Kit (Qiagen). Total amount of RNA was measured using Qubit RNA Broad Range Assay in a Qubit Fluorometer (Life Technologies). cDNA was then synthesized using iScript cDNA Synthesis Kit (Bio-Rad Laboratories, Hercules, CA). We performed gene expression analyses using using RT $^{2}$ Human Cell Death Pathway Finder PCR arrays (PAHS-212Z; Qiagen) in Bio-Rad CFX Connect (Bio-Rad). Data were analyzed by CFX Manager Software using normalized $\left(\Delta \Delta C_{\mathrm{T}}\right)$ method with two housekeeping genes ( $\beta$-actin and glyceraldehyde 3 -phosphate dehydrogenase were both used for normalization after empirically determining the expression for stability in our treatment groups).

Levels of $\beta$-adrenergic receptor and adipogenesis-specific gene expression were also assessed by quantitative RT-PCR. Reactions consisted of $10 \mu \mathrm{l}$ SsoFast Evagreen (1725200, Bio-Rad), $2 \mu \mathrm{l}$ of both forward and reverse primers (at a $10 \mu \mathrm{mol} / \mathrm{l}$ concentration), $2 \mu \mathrm{l}$ cDNA, and $6 \mu \mathrm{l}$ of $\mathrm{H}_{2} \mathrm{O}$. Adipogenesis was assessed by C/EBP $\alpha$ (QT00203357, Qiagen) and PPAR $\gamma 2$ levels (sequence shown in ref. (35)). Expression levels of $\beta 1$ - (QT00204309, Qiagen), ß2- (QT00200011, Qiagen), and $\beta 3$-adrenergic receptors (QT00200004, Qiagen) were measured similarly. Target gene mRNA data were normalized to $\beta$-actin expression (QT01680476, Qiagen). All reactions were performed for 40 cycles using the following temperature profiles: $95^{\circ} \mathrm{C}$ for $2 \mathrm{~min}$ (initial denaturation); and $55^{\circ} \mathrm{C}$ for $12 \mathrm{~s}$ (annealing and extension). Data were analyzed using relative quantity $\left(\Delta C_{\mathrm{T}}\right)$.

\section{Caspase- 3 and Cyclin-D1 Measurements}

Total proteins from the cultured cells were extracted using Cell Extraction Buffer (Life Technologies) with complete protease inhibitor cocktail (Roche Diagnostics, Laval, Quebec). Proteins were measured by BCA Protein Assay Reagent (Pierce BCA Protein Assay Kit, Thermo Scientific, Rockford, IL), and equal amounts were used for active caspase-3 and cyclin-D1 measurements. To measure activated caspase-3, caspase-3 (active) Human ELISA kit (Life Technologies) was used. Data were collected using Thermo Scientific Multiskan FC Microplate Photometer (Thermo Scientific), measuring absorbance at $450 \mathrm{~nm}$. Cyclin-D1 level was measured similarly using PathScan Total Cyclin-D1 Sandwich ELISA kit (Cell Signaling Technology, Danvers, MA).

\section{Adipogenic Differentiation}

To induce adipogenic differentiation, hemSCs were seeded at a density of 40,000 cells $/ \mathrm{cm}^{2}$ in StemPro Adipogenesis differentiation medium (Adipo media; Life Technologies). Control medium consisted of Dulbecco's Modified Eagle Medium supplemented with $10 \%$ fetal bovine serum. Medium was changed every other day. RNA was isolated from cells after $7 \mathrm{~d}$ to perform quantitative RT-PCR for $\beta$-adrenergic receptor expression. To determine whether cell growth/ proliferation may alter adipogenesis, we pretreated hemSCs with $10 \mu \mathrm{g} / \mathrm{ml}$ mitomycin C (MitoC; Sigma Aldrich, Oakville, ON) for $2 \mathrm{~h}$.
Cells were then washed, resuspended, and plated at $40,000 \mathrm{cells} / \mathrm{cm}^{2}$ in adipogenesis media. RNA was isolated at day 4 to assay for $\mathrm{C} / \mathrm{EBP} \alpha$ and PPAR $\gamma 2$ levels (transcription factors essential for adipogenic differentiation) (33-35).

\section{Statistical Analysis}

The data were expressed as mean \pm SEM. Where appropriate, corrected ANOVA or two-tailed Student's unpaired $t$ tests were performed. $P$ values $<0.05$ were considered statistically significant.

\section{STATEMENT OF FINANCIAL SUPPORT}

This study was funded by the Canadian Institutes of Health Research (Z.A.K.; MOP 97783). Z.A.K. is a recipient of a New Investigator Award from the Heart and Stroke Foundation of Canada (Great-West Life and London Life New Investigator Award).

\section{Disclosure: No conflicts to declare.}

\section{REFERENCES}

1. Mulliken, J.B. \& Glowacki, J. Hemangiomas and vascular malformations in infants and children: a classification based on endothelial characteristics. Plast. Reconstr. Surg. 69, 412-422 (1982).

2. Krol, A. \& MacArthur, C.J. Congenital hemangiomas: rapidly involuting and noninvoluting congenital hemangiomas. Arch. Facial Plast. Surg. 7, 307-311 (2005).

3. Kleiman, A., Keats, E.C., Chan, N.G. \& Khan, Z.A. Evolution of hemangioma endothelium. Exp. Mol. Pathol. 93, 264-272 (2012).

4. Frieden, I.J., Eichenfield, L.F., Esterly, N.B., Geronemus, R. \& Mallory, S.B. Guidelines of care for hemangiomas of infancy. American Academy of Dermatology Guidelines/Outcomes Committee. J. Am. Acad. Dermatol. 37, 631-637 (1997).

5. Durr, M.L., Meyer, A.K., Huoh, K.C., Frieden, I.J. \& Rosbe, K.W. Airway hemangiomas in PHACE syndrome. Laryngoscope 122, 2323-2329 (2012).

6. Léauté-Labrèze, C., Dumas de la Roque, E., Hubiche, T., Boralevi, F., Thambo, J.B. \& Taïeb, A. Propranolol for severe hemangiomas of infancy. N. Engl. J. Med. 358, 2649-2651 (2008).

7. Price, C.J. et al. Propranolol vs corticosteroids for infantile hemangiomas: a multicenter retrospective analysis. Arch. Dermatol. 147, 1371-1376 (2011).

8. Richter, G.T. \& Friedman, A.B. Hemangiomas and vascular malformations: current theory and management. Int. J. Pediatr. 2012, 645678 (2012).

9. Lamy, S., Lachambre, M.P., Lord-Dufour, S. \& Béliveau, R. Propranolol suppresses angiogenesis in vitro: inhibition of proliferation, migration, and differentiation of endothelial cells. Vascul. Pharmacol. 53, 200-208 (2010).

10. Bingham, M.M., Saltzman, B., Vo, N.J. \& Perkins, J.A. Propranolol reduces infantile hemangioma volume and vessel density. Otolaryngol. Head. Neck Surg. 147, 338-344 (2012).

11. Hogeling, M., Adams, S. \& Wargon, O. A randomized controlled trial of propranolol for infantile hemangiomas. Pediatrics 128, e259-e266 (2011).

12. Stiles, J. et al. Propranolol treatment of infantile hemangioma endothelial cells: a molecular analysis. Exp. Ther. Med. 4, 594-604 (2012).

13. Ji, Y., Li, K., Xiao, X., Zheng, S., Xu, T. \& Chen, S. Effects of propranolol on the proliferation and apoptosis of hemangioma-derived endothelial cells. J. Pediatr. Surg. 47, 2216-2223 (2012).

14. Porter, A.G. \& Jänicke, R.U. Emerging roles of caspase-3 in apoptosis. Cell Death Differ. 6, 99-104 (1999).

15. Xiao, Q., Li, Q., Zhang, B. \& Yu, W. Propranolol therapy of infantile hemangiomas: efficacy, adverse effects, and recurrence. Pediatr. Surg. Int. 29, 575-581 (2013).

16. Georgountzou, A., Karavitakis, E., Klimentopoulou, A., Xaidara, A. \& Kakourou, T. Propranolol treatment for severe infantile hemangiomas: a single-centre 3-year experience. Acta Paediatr. 101, e469-e474 (2012).

17. Bagazgoitia, L., Hernández-Martín, A. \& Torrelo, A. Recurrence of infantile hemangiomas treated with propranolol. Pediatr. Dermatol. 28, 658-662 (2011).

18. Khan, Z.A. et al. Multipotential stem cells recapitulate human infantile hemangioma in immunodeficient mice. J. Clin. Invest. 118, 2592-2599 (2008). 


\section{Articles $\mid$ Kum and Khan}

19. Ji, Y., Chen, S., Li, K., Xiao, X., Zheng, S. \& Xu, T. The role of B-adrenergic receptor signaling in the proliferation of hemangioma-derived endothelial cells. Cell Div. 8, 1 (2013).

20. Stacey, D.W. Cyclin D1 serves as a cell cycle regulatory switch in actively proliferating cells. Curr. Opin. Cell Biol. 15, 158-163 (2003).

21. Wong, A., Hardy, K.L., Kitajewski, A.M., Shawber, C.J., Kitajewski, J.K. \& $\mathrm{Wu}$, J.K. Propranolol accelerates adipogenesis in hemangioma stem cells and causes apoptosis of hemangioma endothelial cells. Plast. Reconstr. Surg. 130, 1012-1021 (2012).

22. Kermer, P., Klöcker, N., Labes, M. \& Bähr, M. Insulin-like growth factorI protects axotomized rat retinal ganglion cells from secondary death via PI3-K-dependent Akt phosphorylation and inhibition of caspase-3 In vivo. J. Neurosci. 20, 2-8 (2000).

23. Shimoke, K. \& Chiba, H. Nerve growth factor prevents 1-methyl-4-phenyl1,2,3,6-tetrahydropyridine-induced cell death via the Akt pathway by suppressing caspase-3-like activity using PC12 cells: relevance to therapeutical application for Parkinson's disease. J. Neurosci. Res. 63, 402-409 (2001).

24. Barber, A.J. et al. Insulin rescues retinal neurons from apoptosis by a phosphatidylinositol 3-kinase/Akt-mediated mechanism that reduces the activation of caspase-3. J. Biol. Chem. 276, 32814-32821 (2001).

25. Mohan, S. et al. Involvement of NF-?B and Bcl2/Bax signaling pathways in the apoptosis of MCF7 cells induced by a xanthone compound Pyranocycloartobiloxanthone A. Phytomedicine 19, 1007-1015 (2012).

26. Kim, H.R. et al. FGF-2 inhibits TNF-a mediated apoptosis through upregulation of Bcl2-A1 and Bcl-xL in ATDC5 cells. BMB Rep. 45, 287-292 (2012).

27. Basile, J.R., Eichten, A., Zacny, V. \& Münger, K. NF-kappaB-mediated induction of $\mathrm{p} 21(\mathrm{Cip} 1 / \mathrm{Waf} 1)$ by tumor necrosis factor alpha induces growth arrest and cytoprotection in normal human keratinocytes. Mol. Cancer Res. 1, 262-270 (2003).

28. Cheng, K. et al. Antiproliferative effect of tumor necrosis factor-alpha on human glioblastoma cells linked with cell cycle arrest in G1 phase. Neurol. Med. Chir. (Tokyo) 34, 274-278 (1994).

29. Hattori, T., Hayashi, H., Chiba, T. \& Onozaki, K. Activation of two distinct anti-proliferative pathways, apoptosis and p38 MAP kinase-dependent cell cycle arrest, by tumor necrosis factor in human melanoma cell line A375. Eur. Cytokine Netw. 12, 244-252 (2001).

30. Communal, C., Singh, K., Sawyer, D.B. \& Colucci, W.S. Opposing effects of beta(1)- and beta(2)-adrenergic receptors on cardiac myocyte apoptosis: role of a pertussis toxin-sensitive G protein. Circulation 100, 2210-2212 (1999).

31. Panjala, S.R., Jiang, Y., Kern, T.S., Thomas, S.A. \& Steinle, J.J. Increased tumor necrosis factor-a, cleaved caspase 3 levels and insulin receptor substrate-1 phosphorylation in the $ß 1$-adrenergic receptor knockout mouse. Mol. Vis. 17, 1822-1828 (2011).

32. Steinle, J.J., Booz, G.W., Meininger, C.J., Day, J.N. \& Granger, H.J. Beta 3 -adrenergic receptors regulate retinal endothelial cell migration and proliferation. J. Biol. Chem. 278, 20681-20686 (2003).

33. Keats, E. \& Khan, Z.A. Unique responses of stem cell-derived vascular endothelial and mesenchymal cells to high levels of glucose. PLoS ONE 7, e38752 (2012).

34. Kleiman, A., Keats, E.C., Chan, N.G. \& Khan, Z.A. Elevated IGF2 prevents leptin induction and terminal adipocyte differentiation in hemangioma stem cells. Exp. Mol. Pathol. 94, 126-136 (2013).

35. Roach, E.E. et al. Intrinsic regulation of hemangioma involution by platelet-derived growth factor. Cell Death Dis. 3, e328 (2012). 